\title{
Intramedullary Nailing of Femoral Shaft Fractures with Compressive Nailing Using Only Distal Dynamic Hole and Proximal Static Hole
}

\author{
Hakan Cift ${ }^{1}$, Engin Eceviz ${ }^{2}$, Necdet Sağlam ${ }^{3}$, Cem Coşkun Avcı $^{3}$, Salih Söylemez ${ }^{4}$, Esat Uygur ${ }^{4}$, \\ Yalçın Turhan ${ }^{5}$, Korhan Ozkan ${ }^{4}$
}

${ }^{1}$ Department of Orthopaedics and Traumatology, Medipol University, İstanbul, Turkey; ${ }^{2}$ Department of Orthopaedics and Traumatology, Kartal Lütfi Kırdar Training and Research Hospital, İstanbul, Turkey; ${ }^{3}$ Department of Orthopaedics and Traumatology, Umraniye Training and Research Hospital, İstanbul, Turkey; ${ }^{4}$ Department of Orthopaedics and Traumatology, Medeniyet University Goztepe Training and Research Hospital, Istanbul, Turkey; ${ }^{5}$ Department of Orthopaedics and Traumatology, Atatürk Public Hospital, Düzce, Turkey.

Email: hakanturancift@yahoo.com, engineceviz@yahoo.com, necdetsaglam@hotmail.com, cemcoskunavci@gmail.com, slhsylmz@gmail.com, esatuygur@gmail.com, yturhan_2000@yahoo.com, korhanozkan76@gmail.com

Received November $13^{\text {th }}, 2013$; revised December $19^{\text {th }}, 2013$; accepted December $25^{\text {th }}, 2013$

Copyright (C) 2014 Hakan Cift et al. This is an open access article distributed under the Creative Commons Attribution License, which permits unrestricted use, distribution, and reproduction in any medium, provided the original work is properly cited. In accordance of the Creative Commons Attribution License all Copyrights ( 2014 are reserved for SCIRP and the owner of the intellectual property Hakan Cift et al. All Copyright (C) 2014 are guarded by law and by SCIRP as a guardian.

\section{ABSTRACT}

Objectives: In this study we aimed to present our treatment results of intramedullary nailing of femoral shaft fractures with compressive nailing using proximal static hole and only distal dynamic hole with one screw. Methods: Forty-three patients who had a fracture of the femoral shaft were managed between 2005 and 2008 with intramedullary nailing and the use of only one screw for distal interlocking. Prospectively we evaluated the union time, possible reoperation, fixation and fracture alignment, range of knee motion and complications. Results: Union occurred within a mean duration of 18.7 weeks. No failures of the fixation and fracture alignment and no more than $1 \mathrm{~cm}$ shortness were detected. The knee range of motion was all more than 90 degree. Only one deep venous thrombosis was detected as complication. Conclusions: Compressive nailing using proximal hole and only distal dynamic hole with one screw is a convenient technique for femur fractures.

\section{KEYWORDS}

Femur Fracture; Intramedullary Nailing; Dynamic Locking

\section{Introduction}

Femoral shaft fractures are usually the result of high velocity trauma and are more common in the younger population; on the other hand, as the population ages, the incidence of femoral shaft fractures in the elderly population also increases due to osteoporosis [1,2] and intramedullary nailing becomes the most common method for the treatment of these fractures [3-7].

With the introduction of static interlocking, disadvantages of dynamic intramedullary nailing like inadequate fixation and rotation problems were overcome $[8,9]$. However, with static interlocking fixation, construct is changed from load sharing to load bearing. Also there is a concern that loads applied to the limb were transferred through the locking screws and the nail; not through the site of the fracture thus decreasing the strength of the callus $[10,11]$.

So, in this study we aimed to present our treatment results of intramedullary nailing of femoral shaft fractures with static interlocking using proximal hole and only distal dynamic hole with one screw and hope to combine the advantages of both static and dynamic interlocking.

\section{Materials and Methods}

Forty-three patients who had a fracture of the femoral shaft were managed between 2005 and 2008, at Goztepe 
Training and Research Hospital with intramedullary nailing and the use of only one screw for distal interlocking.

All patients were available for the follow up and they composed our study group. The ages of the patients ranged from 16 to 87 years (mean: 45.93).

The mechanism of injury was motor vehicle accident at 9 patients, pedestrian motor vehicle accident at 7 , gunshot wound at 6 , and fall from a height at 7 patients and fall at home at 14 patients.

Thirty-four fractures were closed and nine were open. One of the open fractures were grade I and two of them were grade II and six of them were grade III according to the classification of Gustilo and Anderson [12]. Femur fracture was graded according to the criteria of Winquist and Hansen [13] on the basis of percentage of the circumference of the cortex that was fragmented. Twenty fractures had a grade 0 , five grade I, eight grade II, three grade III and seven grade IV. The average interval from the injury to the surgery was 4.5 days.

The patients were followed up at third, sixth weeks and three, six and twelve months postoperatively with clinical and radiographic examination. Mean follow up time was 21.9 months (12 - 50 months).

The location of the fracture was classified according to the area of maximum involvement of the shaft. Twenty-two fractures were proximal (Figure 1(a)), 18 were at the middle of the diaphysis, and 3 were distal third of the femur.

\section{Surgical Technique}

All the operations were performed on a fracture table with the patient supine in traction under image intensifier fluoroscopy with antegrade IM nail (Figure 1(b)) (Smith $\&$ Nephew, Trigen). Canal of the femoral bone is reamed to at least $1 \mathrm{~mm}$ more than the intended diameter of the nail. After the nail is inserted, it is locked with proximal and distal locking screws. The nail had two distal interlocking screw holes. One designed for static and the other oval shaped for dynamic locking allowing of minimal motion between the hole and distal screw interference. In our cases only distal dynamic hole was used and the static hole was left empty. Distal screw was inserted with a freehand technique after insertion of proximal screw with the aid of proximal guide. Antibiotic prophylaxis was continued for twenty four hours postoperatively for patients who had had a closed fracture and for seventy two hours for those who had had an open fracture.

Patients were mobilized with no weight bearing for 4 weeks and quadriceps muscle setting and straight leg raising exercises were also started on the morning after the operation in order to establish the same rehabilitation programme for simple and comminuted fractures.

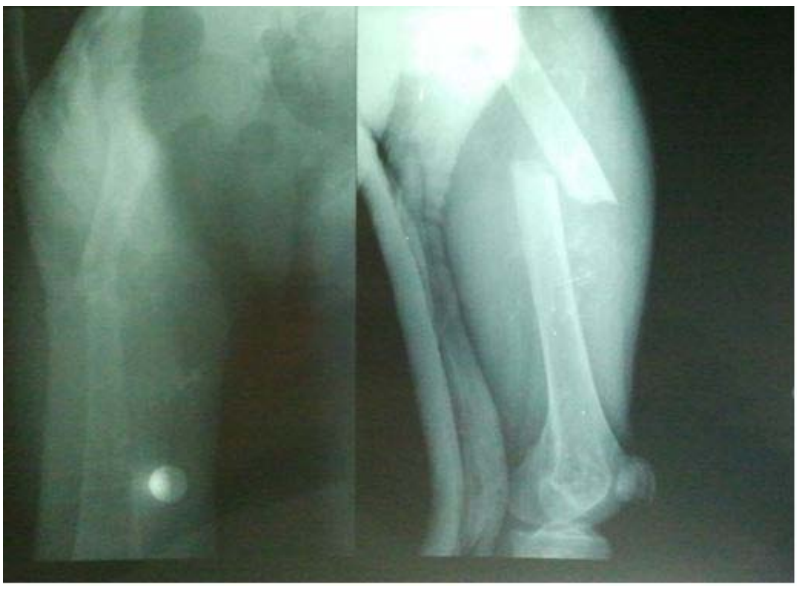

(a)

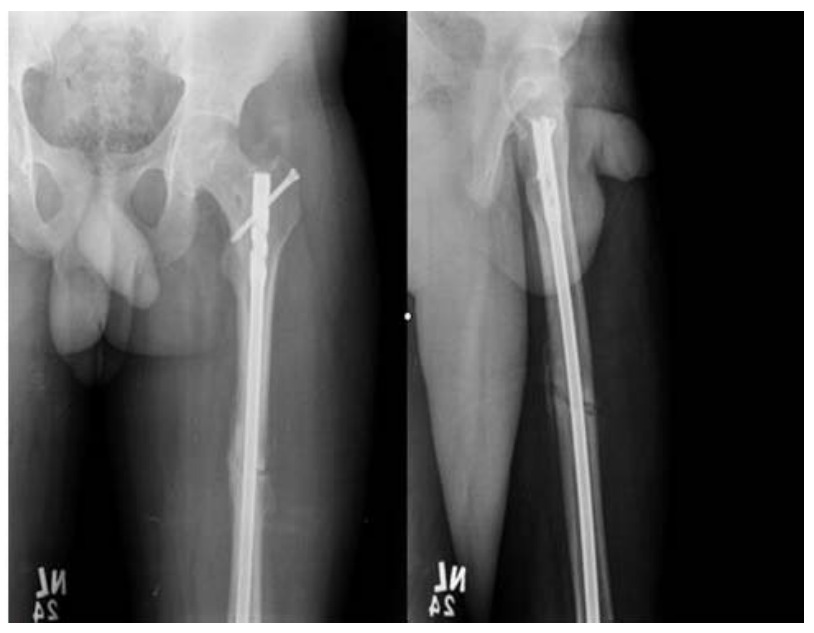

(b)

Figure 1. A proximal femural shaft fracture (a) was treated with an antegrade intrameduller nail (b).

\section{Results}

Closed nailing was performed in 40 patients and mini open in the rest. Mean duration of the operation was 67 minutes (range 52 to 95 minutes).

No patient died in the perioperative and postoperative period. Union occurred in all patients within a mean duration of 18.7 weeks (11 - 29 weeks) and no patient required reoperation to obtain union. Fracture alignment was assessed by clinical examining and $\mathrm{x}$-rays which would better be done using CT scanning.

There were no failures of the fixation and fracture alignment was maintained both in anteroposterior and lateral sections and no shortness of more than $1 \mathrm{~cm}$ was detected at the operated extremity of our patients.

One patient had deep venous thrombosis at his femoral vein on the operated site which was detected with doppler ultrasonography 1 month postoperatively. The range of motion of the knee was $90^{\circ}$ or more in all patients. No 
heterotopic ossification was evident in the abductor muscles of the hips at $\mathrm{x}$-rays of the patients at their latest follow up.

\section{Discussion}

Femoral shaft is the region starting from the distance between $5 \mathrm{~cm}$ distal to the lesser trochanter and $6 \mathrm{~cm}$ proximal to the most distal point of the medial femoral condyle [14].

Fractures of the femoral shaft usually occur as a result of high energy trauma among young patients or after a low energy fall among osteoporotic patients. Today, intramedullary nailing has become the first treatment option for femoral shaft fractures.

Dynamic intramedullary nailing used before the advent of interlocking nailing failed to provide adequate stability against axial and rotational forces hence usually associated with shortening and malrotation of the involved extremity [15]. Static interlocking intramedullary nailing, has overcome many of above mentioned disadvantages however there is a concern that loads applied to the limb were transferred through the locking screws and the nail and not through the site of the fracture thus delaying fracture healing [10,11]. So, dynamization was needed for some cases to have adequate fracture healing treated with static interlocking intramedullary nailing.

Distal cortical hypertrophy is a radiological sign of proximal stress shielding with load concentrations at the tip of the nail. These stresses may lead to mid-thigh pain and fractures around the distal locking screws [10].

Bearing in mind that using only one distal locking screw does not adversely affect the tensional rigidity and axial strength or clinical results of interlocking nailing $[16,17]$ in our series, we had done intramedullary nailing of femoral shaft fractures with static interlocking using proximal hole and only distal dynamic hole with one screw and we had achieved fracture healing in all of our patients including fractures with significant comminution and we did not have to remove the distal screw in any of our cases. We had found no differences in union time of our compressive nailing compared to conventional static intramedullary nailing [18].

\section{Conclusion}

Compressive nailing using proximal hole and only distal dynamic hole with one screw might has physiologic loads to act on the fracture site and combines the advantages of both static and dynamic interlocking without compromising fracture stability.

\section{Funding}

No funds were received in support of this study.

\section{Declaration of Interest}

No benefits in any form have been or will be received from a commercial party related directly or indirectly to the subject of this manuscript.

\section{REFERENCES}

[1] F. Cilli, M. Mahiroğullari, O. Pehlivan, K. Keklikçi, M. Kuşkucu, A. Kiral and S. Avşar, "Treatment of Femoral Shaft Fractures with Expandable Intramedullary Nail," Ulusal Travma Ve Acil Cerrahi Dergisi, Vol. 15, No. 4, 2009, pp. 383-389.

[2] P. Szulc, "Bone Density, Geometry, and Fracture in Elderly Men,” Current Osteoporosis Reports, Vol. 4, No. 2, 2006, pp. 57-63. http://dx.doi.org/10.1007/s11914-006-0003-8

[3] R. J. Brumback, “The Rationales of Interlocking Nailing of the Femur, Tibia, and Humerus," Clinical Orthopaedics And Related Research, Vol. 324, 1996, pp. 292-320.

[4] M. S. Butler, R. J. Brumback, T. S. Ellison, A. Poka, G. H. Bathon and A. R. Burgess, "Interlocking Intramedullary Nailing for Ipsilateral Fractures of the Femoral Shaft and Distal Part of the Femur," Journal of Bone and Joint Surgery American, Vol. 73, 1991, pp. 1492-1502.

[5] R. J. Brumback, P. S. Ellison, A. Poka, R. Lakatos, G. H. Bathon and A. R. Burgess, "Intramedullary Nailing of Open Fractures of the Femoral Shaft," Journal of Bone and Joint Surgery American, Vol. 71, 1989, pp. 13241331.

[6] R. J. Brumback, S. Uwagie-Ero, R. P. Lakatos, A. Poka, G. H. Bathon and A. R. Burgess, "Intramedullary Nailing of Femoral Shaft Fractures. Part II: Fracture-Healing with Static Interlocking Fixation,” Journal of Bone and Joint Surgery American, Vol. 70, 1988, pp. 1453-1462.

[7] R. A. Winquist, "Locked Femoral Nailing," Journal of the American Academy of Orthopaedic Surgeons, Vol. 1, 1993, pp. 95-105.

[8] G. J. Hooper and D. W. Lyon, "Closed Unlocked Nailing for Comminuted Femoral Fractures," Journal of Bone and Joint Surgery British, Vol. 70, 1988, pp. 619-621.

[9] P. D. Hajek, H. R. Bicknell, W. E. Bronson, J. A. Albright and S. Saha, "The Use of One Compared with Two Distal Screws in the Treatment of Femoral Shaft Fractures with Interlocking Intramedullary Nailing. A Clinical and Biomechanical Analysis,” Journal of Bone and Joint Surgery American, Vol. 75, 1993, pp. 519-525.

[10] C. M. Robinson, C. I. Adams, M. Craig, W. Doward, M. C. Clarke and J. Auld, "Implant-Related Fractures of the Femur Following Hip Fracture Surgery,” Journal of Bone and Joint Surgery American, Vol. 84, 2002, pp. 11161122.

[11] D. C. Hardy and K. Drossos, "Slotted Intramedullary Hip Screw Nails Reduce Proximal Mechanical Unloading," Clinical Orthopaedics and Related Research, Vol. 406, 2003, pp. 176-184.

[12] B. D. Horn and M. E. Rettig, "Interobserver Reliability in 
the Gustilo and Anderson Classification of Open Fractures," Journal of Orthopaedic Trauma, Vol. 7, No. 4, 1993, pp. 357-360.

http://dx.doi.org/10.1097/00005131-199308000-00012

[13] R. A. Winquist, S. T. Hansen and D. K. Clawson, "Closed Intramedullary Nailing of Femoral Fractures. A Report of Five Hundred and Twenty Cases," Journal of Bone and Joint Surgery American, Vol. 66, 1984, pp. 529-539.

[14] H. M. Dencker, "Fractures of the Shaft of the Femur. A Clinical Study Based on 1003 Fractures Treated in Swedish Hospitals during the Three-Year Period 1952 to 1954,” Ph.D. Dissertation, University of Gothenburg, Gothenburg, 1963.

[15] J. C. Sharma, S. P. Gupta, N. C. Mathur, R. Kalla, M. K. Aseri, A. Biyani and A. Arora, "Comminuted Femoral Shaft Fractures Treated by Closed Intramedullary Nailing and Functional Cast Bracing,” Journal of Trauma-Injury Infection \& Critical Care, Vol. 34, No. 6, 1993, pp. 786791. http://dx.doi.org/10.1097/00005373-199306000-00006

[16] G. M. White, W. L. Healy, R. J. Brumback, A. R. Burgess and A. F. Brooker, "The Treatment of Fractures of the Femoral Shaft with the Brooker-Wills Distal Locking Intramedullary Nail," Journal of Bone and Joint Surgery American, Vol. 68, 1986, pp. 865-876.

[17] G. A. Hanks, W. C. Foster and J. A. Cardea, "Treatment of Femoral Shaft Fractures with the Brooker-Wills Interlocking Intramedullary Nail," Clinical Orthopaedics and Related Research, Vol. 226, 1988, pp. 206-218.

[18] T. Tuzuner, M. Subasi, A. Kapukaya and N. S. Necmioglu, "Treatment of Femoral Shaft Fractures with Interlocking Intramedullary Nailing,” Acta Orthopaedica Traumatologica Turcica, Vol. 36, 2002, pp. 211-219. 